\title{
Age and Sex as Moderators of the Placebo Response - An Evaluation of Systematic Reviews and Meta-Analyses across Medicine
}

\author{
Katja Weimer ${ }^{a}$ Luana Colloca ${ }^{b}$ Paul Enck ${ }^{a}$ \\ a Psychosomatic Medicine and Psychotherapy, Department of Internal Medicine VI, University Hospital Tübingen,

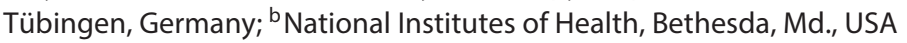

\section{Key Words}

Placebo response $\cdot$ Age $\cdot$ Sex $\cdot$ Randomized controlled

trials $\cdot$ Meta-analyses

\begin{abstract}
Predictors of the placebo response (PR) in randomized controlled trials (RCT) have been searched for ever since RCT have become the standard for testing novel therapies and age and gender are routinely documented data in all trials irrespective of the drug tested, its indication, and the primary and secondary end points chosen. To evaluate whether age and gender have been found to be reliable predictors of the PR across medical subspecialties, we extracted 75 systematic reviews, meta-analyses, and meta-regressions performed in major medical areas (neurology, psychiatry, internal medicine) known for high PR rates. The literature database used contains approximately 2,500 papers on various aspects of the genuine PR. These 'meta-analyses' were screened for statistical predictors of the PR across multiple $\mathrm{RCT}$, including age and gender, but also other patient-based and design-based predictors of higher PR rates. Retrieved papers were sorted for areas and disease categories. Only 15 of the 75 analyses noted an effect of younger age to be associated with higher PR, and this was predominantly in psychiatric conditions but not in depression, and internal medi-
\end{abstract}

cine but not in gastroenterology. Female gender was associated with higher PR in only 3 analyses. Among the patient-based predictors, the most frequently noted factor was lower symptom severity at baseline, and among the design-based factors, it was a randomization ratio that selected more patients to drugs than to placebo, more frequent study visits, and more recent trials that were associated with higher PR rates. While younger age may contribute to the PR in some conditions, sex does not. There is currently no evidence that the PR is different in the elderly. PR are, however, markedly influenced by the symptom severity at baseline, and by the likelihood of receiving active treatment in placebo-controlled trials.

C 2014 S. Karger AG, Basel

\section{Introduction}

Since the introduction of double-blinded and randomized placebo-controlled trials (RCT) in pharmacology and drug development in the middle of the last century, attempts have been made to identify and characterize patients that respond to placebo application with symptom improvement during an RCT [1]. At the same time, ethical concerns have requested to limit the number of patients exposed to placebo to a minimum and to pro-

\section{KARGER 125}

(c) 2014 S. Karger AG, Basel

0304-324X/14/0612-0097\$39.50/0

E-Mail karger@karger.com

www.karger.com/ger
Prof. Dr. Paul Enck

Psychosomatic Medicine and Psychotherapy

Department of Internal Medicine VI, University Hospital Tübingen

Frondsbergstrasse 23, DE-72076 Tübingen (Germany)

E-Mail paul.enck@uni-tuebingen.de 
vide the best treatment available to those seeking health care for acute and chronic conditions [2].

The consequences resulting from this dilemma are numerous design variants that were developed to overcome RCT limitations: single and multiple crossover designs, placebo- and drug run-in phases, randomized and blinded run-ins and withdrawals, enrichment designs with more patients randomized to the drug than to placebo, cluster randomization, step-wedge design, registry trials, Zelen design, and sequential parallel comparison designs, to name just a few [3]. They all have advantages and pitfalls in minimizing the placebo effects in RCT [4].

At the same time, psychologists and trialists have attempted to profile placebo responders in RCT, with much less success than initially thought [5]. Among the many personality traits that have been tested for prediction of placebo responses (PR) specifically in experimental settings, a few have been able to allow generalization across conditions and diseases [6], and certainly most - if not all - have never been tested in large-scale RCT for obvious reasons: if they would demonstrate an identifiable and substantial subset of patients that has to be excluded, this would pose the indication of the drug under testing at risk.

Biomarkers of the PR, especially genetic traits may be the future (e.g. COMT in irritable bowel syndrome, IBS, patients [7]), but currently the list is rather small [7-10], and it appears unlikely that a single genetic polymorphism, e.g. of the oxytocin pathway $[11,12]$, may account for all PR in all medical and clinical conditions.

Under these circumstances, it is not surprising that age and gender issues have repeatedly been named as important contributors (mediators or moderators) to the PR in RCT as they are recorded and documented in all RCT performed; especially the PR in different age groups has frequently been reviewed [13-15]. We recently [16] screened the literature with respect to the question whether children and adolescents exhibit higher PR than adults, and found at least some evidence to supporting this position. Experimental data however, devoted to this question come to the opposite conclusion [17].

Very few data but mostly speculation exist with respect to the question what happens to the PR in the elderly [18]. A narrative review in Gerontology discusses potential outlines in general; however, it does not come to a firm prospect and prediction [19], and experimental data, e.g. testing susceptibility to placebo analgesia procedures across the older age ranges, do not exist.

Theoretically, one may assume three models: either the child-to-adolescent-to-adulthood decrease in the PR that has been proposed before [16] continues (model 1), or it stabilizes and no further change in the PR is noted with reaching adult life (model 2), or the function reverses (model 3). Model 1 would use a 'continuous learning' assumption that blocks the PR in the elderly to operate due to a longer history of successful and failed medicinal interventions. Model 2 (stable PR once adulthood is reached) assumes the major driver of the PR to occur during childhood, when the learning capacity is maximal and expectations are the highest. Model 3 finally assumes a cognitive decline to occur with senescence that may also affect expectations for help to increase again. None of these models is currently supported by strong empirical evidence, and they may vary across diseases and systems.

To approach an answer to this question, we set out to evaluate current evidence for a role of age - and gender in re-analyses of RCT, either as systematic reviews, or as methodologically firm meta-analyses or meta-regressions. In addition to checking for age and gender contributions to the PR, we were interested in other patient- or design-based factors that would be associated with higher PR across different medical conditions.

\section{Methods}

Since 2004, we searched PubMed for articles using the search term 'placebo' both retrospectively and prospectively to select papers dealing with the placebo effect.

For all approximately 100,000 citations retrieved in 2004, we (K.W., P.E.) screened their titles and abstracts retrospectively and excluded papers describing placebo-controlled trials of individual drugs and other medical interventions that 'only' assessed differences between drug and placebo for evaluation of therapeutic benefits of the therapy. We also excluded meta-analyses of placebocontrolled trials and respective reviews. After exclusion of letters and editorials, we were left with approximately 1,000 papers (or approximately $1 \%$ of all papers screened) that discussed different aspects of the PR and/or placebo effects in different medical and psychological subspecialties. These were predominantly experimental data (exploring the different mechanisms of the PR) and reviews, systematic reviews, re-analyses and meta-analyses of RCT data. PDFs of these papers were retrieved and stored in an EndNote database.

Since 2004, we prospectively screen all papers published on a weekly basis ever since (total paper count: 170,855 as of April 4, 2014) using the same search term 'placebo'. In 2010, we added the search term 'nocebo' (230 citations as of April 4, 2014). We occasionally added papers that explored and discussed psychosocial contributions to placebo-like effects even without using the term placebo, e.g. Kunz et al. [20].

This database currently contains approximately 2,500 papers of various aspects of the placebo and nocebo response in medicine and beyond. The distribution of these papers on the genuine placebo and nocebo effects between 1960 and 2014 is depicted in
98

Gerontology 2015;61:97-108 DOI: 10.1159/000365248
Weimer/Colloca/Enck 


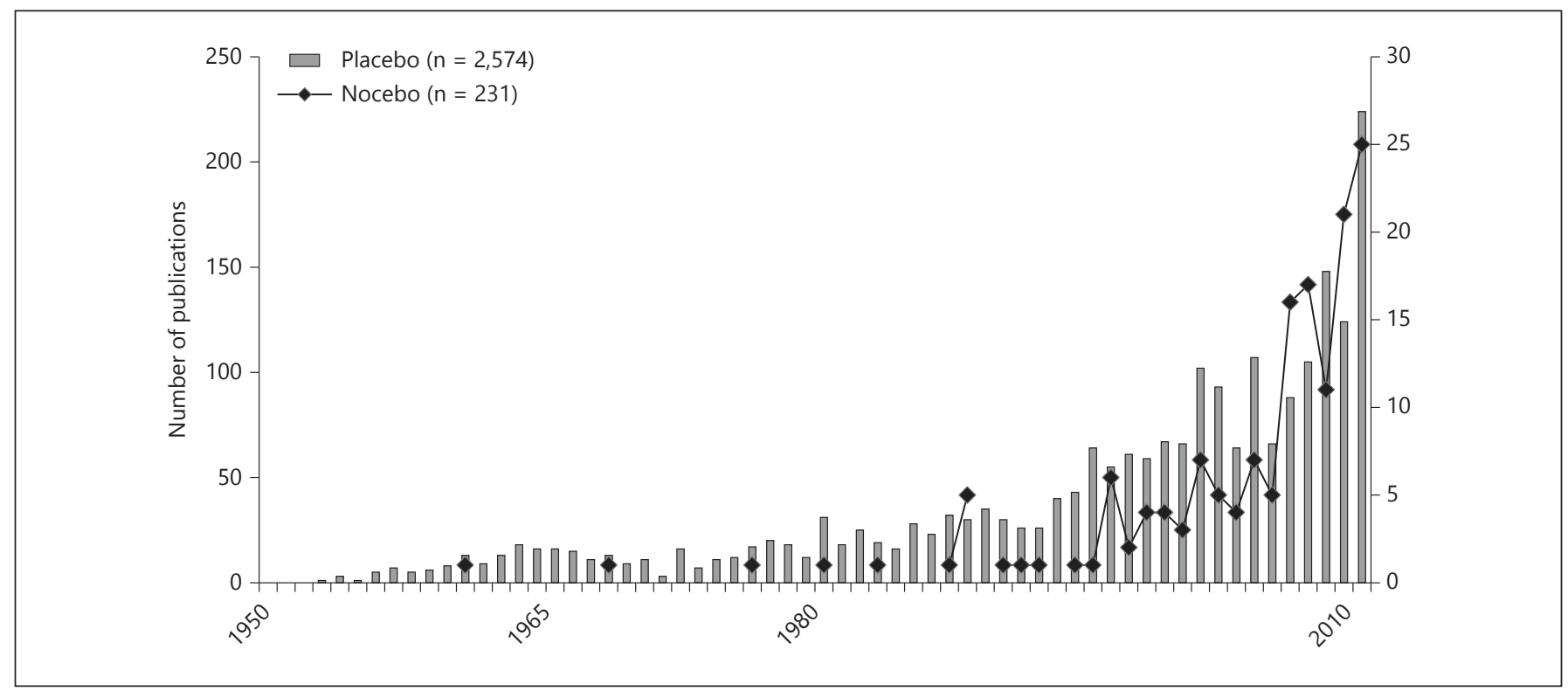

Fig. 1. Yearly publication of genuine papers on the placebo and nocebo response in PubMed between 1950 and 2012.

figure 1 , and demonstrates an exponential increase, similar to the increase seen in the remaining placebo literature.

This database was hand-searched by all authors for systematic reviews, meta-analyses, and meta-regressions of the placebo effects and its determinants (mediators, moderators) in various medical specialties, supplemented by papers found in these papers and entered into our database. This way, we identified 75 systematic reviews, meta-analyses and meta-regressions that were used for this systematic review.

Each of these papers was then screened for whether age and gender were included in the analysis, and whether they were explicitly found as moderators of the PR in the placebo arm of respective trials, irrespective of the type of statistical analysis (ANOVA, regression, multiple regression, meta-regression) that was used to identify it. To not over- or underestimate the respective findings, we categorized the potential contribution of age and sex with 'yes' or 'no' only, based on the paper's own evaluation.

We also noted whether and which other patient or design factors in the trials were found to contribute to the size of the PR.

\section{Results}

The 75 systematic reviews, meta-analyses and meta-regressions were sorted into 6 disease groups: neurological diseases (Parkinson's disease, restless leg syndrome, epilepsy, excluding pain: 9 papers), pain syndromes (migraine, neuropathic pain, fibromyalgia, excluding visceral pain: 13 papers), psychiatric diseases [schizophrenia, mania, psychosis, attention-deficit hyperactivity disorder (ADHD), addiction, excluding depression: 17 papers], de- pression (15 papers), gastrointestinal disorders [IBS, functional dyspepsia (FD), inflammatory bowel diseases: 12 papers], and other mixed disorders [asthma, overactive bladder $(\mathrm{OAB})$, hypertension, allergy, chronic fatigue, sleep problems: 10 papers]; one paper meta-analyzed 2 diseases.

It should be noted that these 75 analyses (which we will refer to collectively as 'meta-analyses' in the following) used quite different methodologies for their respective analyses on the one hand, which makes a direct comparison difficult if not impossible. On the other hand, the papers selected from the body of literature (mostly randomized, placebo-controlled trials, sometimes including comparator trials with two or more drugs) may substantially overlap within a condition but were frequently based of different selection and quality criteria. It is therefore conceivable that in some conditions (e.g. in depression) similar mediators and moderators are reported by different analyses, while in other cases, analyses may not have been able to replicate previous analyses.

Furthermore, only a minority of all papers $(n=20)$ were based on individual patient data available, while all other are referring to the published reports (or data reports to the drug approval authorities) that usually only contain means and standard deviations of the data on the age of patients, and percentage of males/females in the respective treatment groups.

Major findings within and across clinical conditions will subsequently be discussed for each of the medical 
Table 1. Meta-analyses of RCT in neurological disorders

\begin{tabular}{lccclllll}
\hline First author & Year & Ref. & $\mathrm{n}$ & Disease & Age & Sex & PR is higher with & PR is also higher with \\
\hline Burneo & 2002 & 21 & 31 & epilepsy & no & NR & & no other factor identified \\
Rheims & 2008 & 22 & 32 & epilepsy & yes & no & lower age & no other factor identified \\
Schmidt & 2013 & 23 & $3^{*}$ & epilepsy & yes & no & higher age & lower baseline severity \\
Fulda & 2008 & 24 & 36 & RLS & no & no & & longer trial duration \\
Ondo & 2013 & 25 & $6^{*}$ & RLS & no & yes & female sex & lower baseline severity \\
Goetz & 2000 & 26 & $1^{*}$ & Parkinson & no & no & & no other factor identified \\
Goetz & 2008 & 27 & $2^{*}$ & Parkinson & yes & no & higher age & lower baseline severity \\
Goetz & 2008 & 28 & $11^{*}$ & Parkinson & no & no & & higher baseline severity \\
Ondo & 2007 & 29 & $2^{*}$ & Parkinson & yes & no & higher age & no other factor identified \\
\hline
\end{tabular}
able.

$\mathrm{RSL}=$ Restless leg syndrome; $\mathrm{NR}=$ not reported; $\mathrm{n}=$ number of studies analyzed; asterisk indicates that individual data were avail-

Table 2. Meta-analyses of RCT in pain disorders

\begin{tabular}{|c|c|c|c|c|c|c|c|c|}
\hline Diener & 1999 & 30 & 15 & migraine & NR & NR & \multirow{12}{*}{$\begin{array}{l}\text { lower age } \\
\text { lower age }\end{array}$} & higher drug chance \\
\hline Macedo & 2006 & 31 & 98 & migraine & no & no & & European studies \\
\hline Macedo & 2008 & 32 & 32 & migraine & NR & NR & & European studies \\
\hline Ho & 2009 & 33 & 8 & migraine & yes & no & & lower prior triptan use \\
\hline Sun & 2013 & 34 & 7 & migraine & yes & NR & & early response \\
\hline Meissner & 2013 & 35 & 79 & migraine & no & no & & type of placebo \\
\hline Quessy & 2008 & 37 & 35 & neuropathic pain & NR & NR & & higher drug chance \\
\hline Kamper & 2008 & 38 & 44 & pain 1 & NR & NR & & no other factor identified \\
\hline Zhang & 2008 & 39 & 193 & osteoarthritis & no & no & & lower baseline severity \\
\hline Häuser & 2011 & 40 & 72 & fibromyalgia & no & no & & lower baseline severity \\
\hline Häuser & 2011 & 40 & 70 & $\mathrm{DPN}$ & no & no & & lower baseline severity \\
\hline Capurso & 2012 & 41 & 7 & pancreatitis & no & no & & more study sites \\
\hline
\end{tabular}

DPN = Diabetic polyneuropathy; NR = not reported; $\mathrm{n}=$ number of studies analyzed.

subgroups, with a special emphasis of whether or not age and gender have been noted as contributing factors to the size of the PR.

\section{Neurological Trials (Excluding Pain)}

Table 1 reports results from 9 meta-analyses in Parkinson's disease $(n=4)$, restless leg syndrome $(n=2)$, and epilepsy $(\mathrm{n}=3)$. Two Parkinson's disease analyses noted higher PR with older age among adults [27,29], while of the two analyses that expressively investigated age aspects (children vs. adults) in epilepsy, only one [22] could substantiate that the PR is double as high in children (19\%) compared to adults (9.9\%) while the other found the opposite [23]. Only one of the 7 reports noted higher PR in females [25].
Among the other factors identified to predict higher PR in more than one analysis are lower baseline severity of epilepsy, restless leg symptoms, and PD [23, 25, 27], but one analysis [28] found higher baseline severity to be associated with higher PR in PD.

\section{Pain Trials}

The meta-analyses of pain trials across different pain conditions include migraine $(\mathrm{n}=6)$, neuropathic pain $(\mathrm{n}=3)$, and dental pain, osteoarthritis, fibromyalgia, and pain in pancreatitis ( $\mathrm{n}=1$ each; table 2 ). In none of the analyses was gender noted as the predictor of the PR, and in only two migraine analyses $[33,34]$ was age noted as a predictor. 
Table 3. Meta-analyses of RCT in psychiatric disorders

\begin{tabular}{lccclllll}
\hline First author & Year & Ref. & n & Disease & Age & Sex & PR is higher with & PR is also higher with \\
\hline Woods & 2005 & 42 & 32 & schizophrenia & no & no & higher chance of drug \\
Kemp & 2010 & 43 & 28 & schizophrenia & NR & NR & & lower baseline severity \\
Mallinckrodt & 2010 & 44 & 27 & schizophrenia & no & yes female sex & higher change of drug \\
Chen & 2010 & 45 & 31 & schizophrenia & yes & no & lower age & lower baseline severity \\
Potkin & 2011 & 46 & $3^{*}$ & schizophrenia & no & no & lower baseline severity \\
Agid & 2013 & 47 & 50 & psychosis & yes & no & lower age & higher baseline severity \\
King & 2013 & 48 & $1^{*}$ & autism, children & no & no & lower symptom severity \\
Sysko & 2007 & 49 & 20 & bipolar mania & NR & NR & recent studies \\
Yildiz & 2011 & 50 & 38 & bipolar mania & yes & yes higher age, female sex & recent studies \\
Cohen & 2010 & 51 & 40 & OCD, anxiety & yes & no & lower age & lower baseline severity \\
Newcorn & 2009 & 52 & 10 & ADHD children & yes & no & lower age & medication-naïve patients \\
Waxmonsky & 2011 & 53 & $2^{*}$ & ADHD & yes & no & higher age (adults) & higher baseline severity (adults only) \\
Buitelaar & 2012 & 54 & $2^{*}$ & ADHD adults & yes & no & lower age & higher baseline severity \\
Blom & 2014 & 55 & $10^{*}$ & BED & no & no & & lower baseline severity \\
Green & 2010 & 56 & 107 & smoking & NR & NR & no industry support \\
Litten & 2013 & 57 & 48 & alcohol & yes & NR & lower age & recent studies \\
Moore & 2012 & 58 & 28 & addictions & NR & NR & & no other factor identified
\end{tabular}

$\mathrm{BED}=$ Binge eating disorder; $\mathrm{NR}=$ not reported; $\mathrm{n}=$ number of studies analyzed; asterisk indicates availability of individual patient data .

Lower baseline pain intensity was noted as a predictor in 3 analyses [39, 40]. Among study characteristics, a higher chance for drugs resulted in higher PR in two instances [30,37], European studies were reported to have higher PR as compared to studies in the US [31, 32], as well as a higher number of study sites [41].

\section{Psychiatric Trials (Excluding Depression)}

Of the 17 meta-analyses in psychiatric disorders, trials in schizophrenia $(n=6)$ received the most attention, followed by addiction therapy $(\mathrm{n}=3), \operatorname{ADHD}(\mathrm{n}=3)$, bipolar mania $(\mathrm{n}=2)$, and autism, binge eating disorders, and obsessive-compulsive disorder/anxiety (OCD; $\mathrm{n}=1$ each; table 3). Five analyses were based on individual data.

Eight analyses reported age-related differences in the $\mathrm{PR}$, however with different trends. Younger age was associated with higher PR in schizophrenia [45, 47], OCD [51], ADHD in children and adults [52, 54], and treatment of alcohol dependence [57], while in bipolar mania and one adult ADHD analysis, higher PR was associated with higher age $[50,53]$. Two analyses only noted higher PR in females $[44,50]$.

Lower baseline severity of symptoms was the most frequently noted patient-based predictor of high PR ( 5 analyses [43, 45, 46, 51, 55] across all conditions), while in ADHD in adults, higher baseline severity was associated with higher PR [53, 54], similar to schizophrenia [47]. More recent trials produced higher PR [49, 50, 57], as did a higher randomization ratio to drug [42].

\section{Depression Trials}

Depression trials represent the largest single clinical entity that has been meta-analyzed for predictors of the PR; in fact, increasing PR rates in more recent trials were noted first in depression [60] and mark the starting point for the increase in placebo research in the early years of the 21 st century (see above, fig. 1).

The 15 meta-analyses included in table 4 include 3 with individualized data $[59,69,73]$.

Only one analysis [65] noted an influence of age on the PR (higher PR in patients below age 65), none reported an influence of sex on the PR.

Among the patient-based characteristics of high PR, lower baseline severity $[59,64-66,72]$ was noted as predictive, as was worsening of symptoms during screening and study start [62], and treatment-naïve patients [69]. In contrast to most other meta-analyses, one analysis noted higher baseline severity of symptoms to be associated with higher PR [61].

In more recent trials [60], a higher randomization ratio [68] and European studies [63] were linked to higher PR. Another design factor associated with higher PR was a higher number of study visits [70, 73]. 
Table 4. Meta-analyses of RCT in depression

\begin{tabular}{lllrlllll}
\hline First author & Year & Ref. & n & Disease & Age & Sex & PR is higher with & PR is also higher with \\
\hline Brown & 1992 & 59 & $1^{*}$ & depression & no & no & lower baseline severity \\
Walsh & 2002 & 60 & 75 & depression & NR & NR & recent studies \\
Khan & 2002 & 61 & 45 & depression & NR & NR & higher baseline severity \\
Evans & 2004 & 62 & 4 & depression & no & no & symptom worsening before start \\
Stein & 2006 & 63 & 12 & GAD, PD, MDD & no & no & European studies \\
Kirsch & 2008 & 64 & 35 & depression & no & NR & lower baseline severity \\
Papakostas & 2009 & 65 & 182 & depression & yes & NR & lower age (<65 years) & lower baseline severity \\
Bridge & 2009 & 66 & 12 & depression, children & NR & no & lower baseline severity \\
Brunoni & 2009 & 67 & 41 & depression & no & no & rTMS as add-on therapy \\
Sinyor & 2010 & 68 & 91 & depression & NR & NR & higher chances for drug \\
Hunter & 2010 & 69 & $1^{*}$ & depression & no & no & treatment-naïe patients \\
Rutherford & 2011 & 70 & 11 & depression, children & no & NR & no other factor identified \\
Gueorguiva & 2011 & 71 & 7 & depression & no & no & lower baseline severity \\
Khin & 2011 & 72 & 81 & depression & NR & NR & higher number of study visits \\
Mancini & 2014 & 73 & $14^{*}$ & depression & no & NR & \\
\hline
\end{tabular}

$\mathrm{GAD}=$ General anxiety disorder; $\mathrm{PD}=$ panic disorder; $\mathrm{MDD}=$ major depression disorder; $\mathrm{rTMS}=$ repetitive transcranial magnetic stimulation; $\mathrm{NR}=$ not reported; $\mathrm{n}=$ number of studies analyzed; asterisk indicates availability of individual patient data.

Table 5. Meta-analyses of RCT in gastrointestinal disorders

\begin{tabular}{|c|c|c|c|c|c|c|c|c|}
\hline First author & Year & Ref. & $\mathrm{n}$ & Disease & Age & Sex & $\mathrm{PR}$ is higher with & $\mathrm{PR}$ is also higher with \\
\hline Ilnyckyj & 1997 & 74 & 38 & IBD & NR & NR & \multirow{10}{*}{ lower age } & higher number of study visits \\
\hline $\mathrm{Su}$ & 2004 & 75 & 21 & IBD & no & no & & higher number of study visits \\
\hline Pitz & 2005 & 77 & 84 & IBS & yes & no & & higher number of study visits \\
\hline Patel & 2005 & 78 & 45 & IBS & no & no & & lower number of study visits \\
\hline Dorn & 2007 & 79 & 19 & IBS & no & no & & higher number of study visits \\
\hline Talley & 2006 & 81 & $4^{*}$ & functional dyspepsia & no & no & & inconsistent symptoms \\
\hline Enck & 2009 & 82 & $1^{*}$ & functional dyspepsia & no & no & & improvement during run-in \\
\hline De Craen & 1999 & 83 & 79 & duodenal ulcers & NR & NR & & higher application frequency \\
\hline Yuan & 2009 & 84 & 36 & gastric ulcers & no & NR & & $\begin{array}{l}\text { previous gastrointestinal } \\
\text { history }\end{array}$ \\
\hline Cremonini & 2010 & 85 & 24 & reflux disease & no & no & & nonerosive reflux disease \\
\hline
\end{tabular}

IBD = Inflammatory bowel disease; $\mathrm{NR}=$ not reported; $\mathrm{n}=$ number of studies analyzed; asterisk indicates availability of individual patient data.

Trials in Gastrointestinal Disorders

For gastrointestinal disorders, trials in IBS were metaanalyzed most frequently $(n=4)$, followed by inflammatory bowel diseases (Crohn's disease, ulcerative colitis; $\mathrm{n}=3)$, FD $(\mathrm{n}=2)$, and reflux disease and gastric and duodenal ulcers ( $\mathrm{n}=1$ each). Two analyses in FD were based on individualized data [81, 82] (table 5).

One analysis only noted a higher PR in younger patients [77]; none reported gender differences in the PR.
Only a few disease and patient-related features predicted higher PR, especially inconsistent symptom pattern [81], symptom improvement during run-in [82], and a previous history of gastrointestinal symptoms [84].

Among the design features analyzed, a higher number of study visits was predictive of higher PR in ulcerative colitis [74], Crohn's disease [75], IBS [77, 79], while one report in IBS found high PR to be predicted by a lower 
Table 6. Meta-analyses of RCT in other disorders

\begin{tabular}{lccclllll}
\hline First author & Year & Ref. & n & Disease & Age & Sex & PR is higher with & PR is also higher with \\
\hline Lee & 2009 & 86 & 36 & OAB & NR & NR & & lower baseline severity \\
Thijs & 1990 & 87 & $1^{*}$ & hypertension & yes & NR & younger age & no other factor identified \\
Cho & 2005 & 88 & 29 & CFS & no & no & & high intervention intensity \\
Freeman & 1999 & 89 & $2^{*}$ & PMS & yes & NA & younger age & no other factor identified \\
Lamel & 2012 & 90 & 31 & psoriasis & NR & NR & & higher drug chance \\
Narkus & 2013 & 91 & 6 & allergy & NR & NR & & no other factor identified \\
Kemeny & 2007 & 92 & $1^{*}$ & asthma & yes & no & younger age & nother factor identified \\
Wang & 2012 & 93 & 34 & asthma & no & no & & lower baseline severity \\
McCall & 2003 & 94 & 5 & sleep disorders & NR & NR & & no other factor identified \\
McCall & 2011 & 95 & $1^{*}$ & sleep disorders & yes & NR & younger age & no other factor identified \\
\hline
\end{tabular}

CFS = Chronic fatigue syndrome; PMS = premenstrual syndrome; NA = not applicable; $\mathrm{NR}=$ not reported; $\mathrm{n}=$ number of studies analyzed; asterisk indicates availability of individual patient data.

number of office visits [78]. Longer treatment follow-up [76] and higher frequency of drug application [83] were also predictive of the $\mathrm{PR}$.

\section{Trials in Other Diseases}

Ten more meta-analyses report predictors from treatment trials for sleep problems $(n=2)$, asthma $(n=2)$, allergy $(\mathrm{n}=1)$, psoriasis $(\mathrm{n}=1)$, premenstrual syndrome $(\mathrm{n}=1)$, chronic fatigue syndrome $(\mathrm{n}=1)$, hypertension $(\mathrm{n}=1)$ and $\mathrm{OAB}(\mathrm{n}=1)$, of which 4 were based on individual data (table 6).

Four analyses noted higher PR in younger patients [87, $89,92,95]$, while no study found an influence of gender on the PR.

A higher randomization ratio [90] was noted as a design factor driving higher PR in psoriasis, and lower symptom severity at baseline $[86,93]$ as patient-based factor driving the PR.

\section{Discussion}

This systematic review of systematic reviews, metaanalyses and meta-regressions demonstrates both disease-specific as well as disease-unspecific factors driving the PR in RCT, and these factors are either patient or design based.

\section{Age and Gender}

Taken together, our analysis indicates that age and gender appear not to play a role for PR in RCT: only 3 of 75 analyses could identify a contribution of sex towards the PR, and only 15 of the analyses found that PR are higher in younger patients (mostly in psychiatric trials) while another 5 found the opposite. As we have seen especially in analyses involving children and adolescents with ADHD [52-54], these are based on a small number of studies included in the respective meta-analyses and therefore cannot outnumber the many more studies in adults that could not support this hypothesis. Even if the very young patients may show higher PR rates than adolescents and adults under specific circumstances [16], certainly among the three possible models (model 1: further decrease with higher age; model 2: stable after reaching adulthood; model 3: increase again in the elderly), model 2 is the most likely one: studies and analyses including the elderly (above 65 years) $[65,87]$ could not substantiate a further decrease of the PR in this group beyond that of adults.

It is of importance to note that our analysis grossly ignores quality differences in the type of statistical analysis substantiating the findings in the different meta-analyses, and that most studies were based on aggregate (study level) data. For proper patient-related predictors - such as age and gender - meta-analytic approaches based on individual patient data would be more appropriate, as was the case in 20 of the 75 analyses. But even if we only consider only these 20 reports, a similar picture emerges: 5 analyses noted younger age to be associated with higher $\mathrm{PR}$, while 4 found older age to be the driving factor of the $\mathrm{PR}$, and 11 did not find a contribution of age at all. Whether access to individual patient data for more RCT (e.g. in central repository) would allow another conclusion, needs to be shown in the future, but as long as access to individual drug trial data is predominantly controlled by the pharmaceutical industry, this will remain hope only [96]. 
A question remains that we cannot answer at this stage: why are sometimes average PR rates higher in children with ADHD, depression, and autism when compared to overall PR rates in the same condition in adults? The answer is presumably of methodological nature. In $\mathrm{RCT}$, the response in the placebo arm of drug trials is usually a compound effect of different factors such as spontaneous variation of symptoms, regression to the mean, and the specific PR due to expectations and learning [4]. For the evaluation of the true drug benefit 'above placebo', separation of these factors is not necessary and is usually not performed. However, for the characterization of the 'true' PR, it would be essential to include a 'no treatment' control group to identify the contribution of the natural course of the disease [3] to both the drug- and the placebo-treated patients. If done so [97], nearly half of the effect seen in the placebo arm of RCT can be attributed to spontaneous variation of symptoms. With respect to the contribution of age of children, adolescents, adults, and elderly to the PR, a necessary consequence would be to test whether spontaneous variation of symptoms is similar in these different age groups within a single clinical condition (e.g. asthma), which is rather unlikely [98]. And even if so, the PR may still be higher in youth and women because of differences in pathophysiology.

While no-treatment controls are ethically questionable for serious medical conditions, an approximation of the size of spontaneous contribution to the PR in RCTs can be achieved using waiting-list controls that have their own methodological limitations [3] but are frequently conducted in nondrug trials, e.g. with psychotherapy [99]. In one meta-analysis [100] it was shown that the effect of waiting improved baseline depression scores by $33 \%$, while placebo administration accounted for a $40 \%$ improvement. In another study, spontaneous improvement during waiting was $15 \%$ of Hamilton Depression Rating Scale (HAM) baseline values after 4-8 weeks waiting, and $20 \%$ of patients would respond to a degree that would be regarded as significant clinical improvement [101]. In the meta-analysis by Krogsbøll et al. [97], waiting contributed between 0 (insomnia) and $80 \%$ (depression) to the overall placebo effect across a variety of medical conditions.

\section{Patient- and Disease-Based Factors}

Among the patient-based predictors of the PR, the most prominent one that appears across all conditions and diseases except in gastrointestinal disorders is lower severity of the illness at baseline prior to randomization; this was noted in 18 analyses, and a few contrasting reports come only from neurological and psychiatric disor- ders $[28,47,53,54,66]$. Usually, symptom severity is assessed via diagnostic criteria such as the HAM, the Unified Parkinson Disease Rating Scale, the Inattention/ Overactivity with Aggression Conners parent and teacher rating scales in ADHD, and the Rome criteria in IBS, and cutoff criteria are used to ease and standardize enrolment. However, for most of the diseases listed here, these are predominantly physician or patient-reported outcome measures that are known to be susceptible to higher PR as compared to disease biomarkers [102, 103], and are also prone to manipulation during recruitment [104]. Furthermore, it has been shown that (in depression) physician and patient rating of disease severity may vary substantially [105]. The inclusion of patients with low symptom severity in RCT may also be in the interest of the drug industry [106] since it offers a larger market share once the drug has been approved.

Other patient-based or disease-based factors driving the PR have been noted occasionally in individual analyses, such as treatment naïvety in migraine [33], ADHD [52], and depression [69], symptom worsening before the start of the study in depression [62], but symptom improvement during run-in [82] and inconsistent symptom pattern [61] in FD, and early response to therapy [34]. It should be noted that in addition to the factors listed in the tables above, most studies noted more and other patient and design factors contributing to the PR.

\section{Design-Based Factors}

Three of the many factors identified in the meta-analyses stick out as prominent: more recently performed studies report higher PR rates than studies in the past [49, $50,57,60]$, more study visits during the trial $[70,73-75$, $77,79,83$ ], and studies randomizing more patients to drug than to placebo (called unbalanced randomization) $[30,37,42,68]$.

The first two are certainly correlated: over the last 25 years, trial designs have changed substantially from crossover to parallel design, from 4 weeks to 8-12 weeks and even longer [3], and patient monitoring during the trial has intensified, e.g. by using electronic monitoring systems, resulting in more contacts of patients with doctors and trial staff. This underlines the importance of doctor-patient communication as underlying mechanisms for PR within and outside of clinical trials [3]. Associated PR-driving factors are longer trial duration [24] and longer follow-up observations [76]. It should be noted that the number of study visits was explicitly not a predictor of the PR response in pediatric trials in depression in children, while it was in adolescents and adults [70], indicating principle differenc- 
es between children and adults. For children, the concept of 'placebo by proxy' has been put forward [107], but this needs to be explored further also for adults.

It appears also that in some indication areas (migraine, depression, IBS) European studies have produced higher $\mathrm{PR}$ rates than studies in the US $[31,32,63,80]$. Whether this reflects systematic differences in design characteristics between Europe and the US remains to be shown, but it may be linked to more study sites and the increase in multicenter trials [41] in Europe.

The other factor, unbalanced randomization, is of different nature but has been noted as early as 1999 [30]. Recruiting more patients to drug than to placebo may be done for different reasons: for ethical reasons, to allow more patients to receive active treatment, for practical reasons to speed the recruitment process, or for pharmacological reasons, to test different drug doses or different drugs against a single placebo arm. This lowering of chances of patients to be randomized to placebo increases their expectations of subsequent symptom improvement and results in both higher drug as well as PR and decreases the drug-placebo difference, e.g. in depression [65]. This has also been confirmed in experimental studies, e.g. in Parkinson patients [108], and may be due to higher dopamine release as the underlying neurobiological reward mechanism [109].

We need to acknowledge limitations of our analysis. One is that we may have missed relevant information in single RCT that may have - among others - analyzed determinants of the PR in addition to evaluating drug-placebo differences. We restricted ourselves to the analysis of papers (systematic reviews, meta-analyses, meta-regressions) that explicitly focused on the PR and quantified it because otherwise we would not have been able to cover all medical subspecialties simply due to the sheer number of RCT that have been published (more than $100,000)$. We also grossly ignored quality differences in the selected analyses and handled them all rather equally to extract predictor information, despite the fact that extraction errors in meta-analyses are known to be high [110]. This however, allowed us to attempt to screen the whole range of potential predictors of the $\mathrm{PR}-\mathrm{a}$ quantification of these factors was never intended and may even be impossible. Finally, we focused on age and sex as moderators of the PR for this review and listed only one major patient- or design-based predictor per analysis for illustration reasons. Further analyses for single medical subspecialties will show whether or not our listing is unbalanced or incomplete, and likewise, whether age and gender have a different impact across different conditions.

\section{Acknowledgement}

This study was supported by a grant from Deutsche Forschungsgemeinschaft.

\section{References}

1 de Craen AJ, Kaptchuk TJ, Tijssen JG, Kleijnen $\mathrm{J}$ : Placebos and placebo effects in medicine: historical overview. J R Soc Med 1999;92:511-515.

2 Miller FG, Colloca L: The placebo phenomenon and medical ethics: rethinking the relationship between informed consent and riskbenefit assessment. Theor Med Bioeth 2011; 32:229-243.

3 Weimer K, Enck P: Traditional and innovative experimental and clinical trial designs advantages and pitfalls. Handb Exp Pharmacol 2014;225:237-272.

4 Enck P, Bingel U, Schedlowski M, Rief W: The placebo response in medicine: minimize, maximize or personalize? Nat Rev Drug Discov 2013;12:191-204.

5 Kaptchuk TJ, Kelley JM, Deykin A, Wayne PM, Lasagna LC, Epstein IO, Kirsch I, Wechsler ME: Do 'placebo responders' exist? Contemp Clin Trials 2008;29:587-595.

6 Horing B, Weimer K, Enck P: Predictors of placebo effects across symptoms and symptom modalities. Psychosom Med 2014;76: A29.
7 Hall KT, Lembo AJ, Kirsch I, Ziogas DC, Douaiher J, Jensen KB, Conboy LA, Kelley JM, Kokkotou E, Kaptchuk TJ: Catechol-Omethyltransferase val158met polymorphism predicts placebo effect in irritable bowel syndrome. PLoS One 2012;7:e48135.

$\$ 8$ Furmark T, Appel L, Henningsson S, Ahs F, Faria V, Linnman C, Pissiota A, Frans O, Bani M, Bettica P, Pich EM, Jacobsson E, Wahlstedt K, Oreland L, Långström B, Eriksson E, Fredrikson M: A link between serotonin-related gene polymorphisms, amygdala activity, and placebo-induced relief from social anxiety. J Neurosci 2008;28: 13066-13074.

-9 Leuchter AF, McCracken JT, Hunter AM, Cook IA, Alpert JE: Monoamine oxidase a and catechol-o-methyltransferase functional polymorphisms and the placebo response in major depressive disorder. J Clin Psychopharmacol 2009;29:372-377.

-10 Yu R, Gollub RL, Vangel M, Kaptchuk T, Smoller JW, Kong J: Placebo analgesia and reward processing: integrating genetics, per- sonality, and intrinsic brain activity. Hum Brain Mapp DOI: 10.1002/hbm.22496.

11 Enck P, Klosterhalfen S: The story of O - is oxytocin the mediator of the placebo response? Neurogastroenterol Motil 2009;21:347-350.

12 Kessner S, Sprenger C, Wrobel N, Wiech K, Bingel U: Effect of oxytocin on placebo analgesia: a randomized study. JAMA 2013;310: 1733-1735.

13 Franconi F, Campesi I, Occhioni S, Antonini P, Murphy MF: Sex and gender in adverse drug events, addiction, and placebo. Handb Exp Pharmacol 2012;214:107-126.

-14 Tedeschini E, Levkovitz Y, Iovieno N, Ameral VE, Nelson JC, Papakostas GI: Efficacy of antidepressants for late-life depression: a metaanalysis and meta-regression of placebo-controlled randomized trials. J Clin Psychiatry 2011;72:1660-1668.

15 Rutherford BR, Tandler J, Brown PJ, Sneed JR, Roose SP: Clinic visits in late-life depression trials: effects on signal detection and therapeutic outcome. Am J Geriatr Psychiatry 2013;pii:S1064-7481(13)00350-3. 
16 Weimer K, Gulewitsch MD, Schlarb AA, Schwille-Kiuntke J, Klosterhalfen S, Enck P: Placebo effects in children: a review. Pediatr Res 2013;74:96-102.

17 Fadai T: Placebo analgesia in children compared to adults (poster); in IASP Congr, Milan, August 2012.

18 Cherniack EP: Would the elderly be better off if they were given more placebos? Geriatr Gerontol Int 2010;10:131-137.

19 Bingel U, Colloca L, Vase L: Mechanisms and clinical implications of the placebo effect: is there a potential for the elderly? A mini-review. Gerontology 2011;57:354-363.

20 Kunz M, Rainville P, Lautenbacher S: Operant conditioning of facial displays of pain. Psychosom Med 2011;73:422-431.

21 Burneo JG, Montori VM, Faught E: Magnitude of the placebo effect in randomized trials of antiepileptic agents. Epilepsy Behav 2002; 3:532-534.

22 Rheims S, Cucherat M, Arzimanoglou A, Ryvlin P: Greater response to placebo in children than in adults: a systematic review and meta-analysis in drug-resistant partial epilepsy. PLoS Med 2008;5:e166.

-23 Schmidt D, Beyenburg S, D’Souza J, Stavem $\mathrm{K}$ : Clinical features associated with placebo response in refractory focal epilepsy. Epilepsy Behav 2013;27:393-398.

-24 Fulda S, Wetter TC: Where dopamine meets opioids: a meta-analysis of the placebo effect in restless legs syndrome treatment studies. Brain 2008;131:902-917.

-25 Ondo WG, Hossain MM, Gordon MF, Reess $\mathrm{J}$ : Predictors of placebo response in restless legs syndrome studies. Neurology 2013;81: 193-194.

-26 Goetz CG, Leurgans S, Raman R, Stebbins GT: Objective changes in motor function during placebo treatment in PD. Neurology 2000; 54:710-714.

27 Goetz CG, Laska E, Hicking C, Damier P, Müller T, Nutt J, Warren Olanow C, Rascol O, Russ H: Placebo influences on dyskinesia in Parkinson's disease. Mov Disord 2008;23: 700-707.

-28 Goetz CG, Wuu J, McDermott MP, Adler CH, Fahn S, Freed CR, Hauser RA, Olanow WC, Shoulson I, Tandon PK, Parkinson Study Group, Leurgans S: Placebo response in Parkinson's disease: comparisons among 11 trials covering medical and surgical interventions. Mov Disord 2008;23:690-699.

29 Ondo WG: Placebo response in Parkinson trials using patient diaries: sites do matter. Clin Neuropharmacol 2007;30:301-304.

-30 Diener HC, Dowson AJ, Ferrari M, Nappi G, Tfelt-Hansen P: Unbalanced randomization influences placebo response: scientific versus ethical issues around the use of placebo in migraine trials. Cephalalgia 1999;19:699-700.

-31 Macedo A, Farré M, Baños JE: A meta-analysis of the placebo response in acute migraine and how this response may be influenced by some of the characteristics of clinical trials. Eur J Clin Pharmacol 2006;62:161-172.
32 Macedo A, Baños JE, Farré M: Placebo response in the prophylaxis of migraine: a metaanalysis. Eur J Pain 2008;12:68-75.

33 Ho TW, Fan X, Rodgers A, Lines CR, Winner P, Shapiro RE: Age effects on placebo response rates in clinical trials of acute agents for migraine: pooled analysis of rizatriptan trials in adults. Cephalalgia 2009;29:711-718.

34 Sun H, Bastings E, Temeck J, Smith PB, Men A, Tandon V, Murphy D, Rodriguez W: Migraine therapeutics in adolescents: a systematic analysis and historic perspectives of trip$\tan$ trials in adolescents. JAMA Pediatr 2013; 167:243-249.

35 Meissner K, Fässler M, Rücker G, Kleijnen J, Hróbjartsson A, Schneider A, Antes G, Linde K: Differential effectiveness of placebo treatments: a systematic review of migraine prophylaxis. JAMA Intern Med 2013;173:1941-1951.

36 Averbuch M, Katzper M: Gender and the placebo analgesic effect in acute pain. Clin Pharmacol Ther 2001;70:287-291.

37 Quessy SN, Rowbotham MC: Placebo response in neuropathic pain trials. Pain 2008; 138:479-483.

- 38 Kamper SJ, Machado LA, Herbert RD, Maher CG, McAuley JH: Trial methodology and patient characteristics did not influence the size of placebo effects on pain. J Clin Epidemiol 2008;61:256-260.

39 Zhang W, Robertson J, Jones AC, Dieppe PA, Doherty M: The placebo effect and its determinants in osteoarthritis: meta-analysis of randomised controlled trials. Ann Rheum Dis 2008;67:1716-1723.

40 Häuser W, Bartram-Wunn E, Bartram C, Reinecke H, Tölle T: Systematic review: placebo response in drug trials of fibromyalgia syndrome and painful peripheral diabetic neuropathy-magnitude and patient-related predictors. Pain 2011;152:1709-1717.

-41 Capurso G, Cocomello L, Benedetto U, Cammà $\mathrm{C}$, Delle Fave G: Meta-analysis: the placebo rate of abdominal pain remission in clinical trials of chronic pancreatitis. Pancreas 2012;41:1125-1131.

42 Woods SW, Gueorguieva RV, Baker CB, Makuch RW: Control group bias in randomized atypical antipsychotic medication trials for schizophrenia. Arch Gen Psychiatry 2005; 62:961-970

43 Kemp AS, Schooler NR, Kalali AH, Alphs L, Anand R, Awad G, Davidson M, Dubé S, Ereshefsky L, Gharabawi G, Leon AC, Lepine JP, Potkin SG, Vermeulen A: What is causing the reduced drug placebo difference in recent schizophrenia clinical trials and what can be done about it? Schizophr Bull 2010;36:504509.

44 Mallinckrodt CH, Zhang L, Prucka WR, Millen BA: Signal detection and placebo response in schizophrenia: parallels with depression. Psychopharmacol Bull 2010;43:53-72.

45 Chen YF, Wang SJ, Khin NA, Hung HM, Laughren TP: Trial design issues and treatment effect modeling in multi-regional schizophrenia trials. Pharm Stat 2010;9:217-229.
46 Potkin S, Agid O, Siu C, Watsky E, Vanderburg D, Remington G: Placebo response trajectories in short-term and long-term antipsychotic trials in schizophrenia. Schizophr Res 2011;132:108-113.

47 Agid O, Siu CO, Potkin SG, Kapur S, Watsky E, Vanderburg D, Zipursky RB, Remington G: Meta-regression analysis of placebo response in antipsychotic trials, 1970-2010. Am J Psychiatry 2013;170:1335-1344.

48 King BH, Dukes K, Donnelly CL, Sikich L, McCracken JT, Scahill L, Hollander E, Bregman JD, Anagnostou E, Robinson F, Sullivan L, Hirtz D: Baseline factors predicting placebo response to treatment in children and adolescents with autism spectrum disorders: a multisite randomized clinical trial. JAMA Pediatr 2013;167:1045-1052.

49 Sysko R, Walsh BT: A systematic review of placebo response in studies of bipolar mania. J Clin Psychiatry 2007;68:1213-1217.

50 Yildiz A, Vieta E, Tohen M, Baldessarini RJ: Factors modifying drug and placebo responses in randomized trials for bipolar mania. Int J Neuropsychopharmacol 2011;14:863-875.

51 Cohen D, Consoli A, Bodeau N, PurperOuakil D, Deniau E, Guile JM, Donnelly C: Predictors of placebo response in randomized controlled trials of psychotropic drugs for children and adolescents with internalizing disorders. J Child Adolesc Psychopharmacol 2010;20:39-47.

52 Newcorn JH, Sutton VK, Zhang S, Wilens T, Kratochvil C, Emslie GJ, D'souza DN, Schuh LM, Allen AJ: Characteristics of placebo responders in pediatric clinical trials of attention-deficit/hyperactivity disorder. J Am Acad Child AdolescPsychiatry 2009; 48:11651172.

53 Waxmonsky JG, Waschbusch DA, Glatt SJ, Faraone SV: Prediction of placebo response in 2 clinical trials of lisdexamfetamine dimesylate for the treatment of ADHD. J Clin Psychiatry 2011;72:1366-1375.

54 Buitelaar JK, Sobanski E, Stieglitz RD, Dejonckheere J, Waechter S, Schäuble B: Predictors of placebo response in adults with attention-deficit/hyperactivity disorder: data from 2 randomized trials of osmotic-release oral system methylphenidate. J Clin Psychiatry 2012;73:1097-1102.

55 Blom TJ, Mingione CJ, Guerdjikova AI, Keck PE Jr, Welge JA, McElroy SL: Placebo response in binge eating disorder: a pooled analysis of 10 clinical trials from one research group. Eur Eat Disord Rev 2014;22:140-146.

56 Greene NM, Taylor EM, Gage SH, Munafò MR: Industry funding and placebo quit rate in clinical trials of nicotine replacement therapy: a commentary on Etter et al. (2007). Addiction 2010;105:2217-2218.

57 Litten RZ, Castle IJ, Falk D, Ryan M, Fertig J, Chen CM, Yi HY: The placebo effect in clinical trials for alcohol dependence: an exploratory analysis of 51 naltrexone and acamprosate studies. Alcohol Clin Exp Res 2013;37: 2128-2137. 
58 Moore RA, Aubin HJ: Do placebo response rates from cessation trials inform on strength of addictions? Int J Environ Res Public Health 2012;9:192-211.

59 Brown WA, Johnson MF, Chen MG: Clinical features of depressed patients who do and do not improve with placebo. Psychiatry Res 1992;41:203-214.

-60 Walsh BT, Seidman SN, Sysko R, Gould M: Placebo response in studies of major depression: variable, substantial, and growing. JAMA 2002;287:1840-1847.

-61 Khan A, Leventhal RM, Khan SR, Brown WA: Severity of depression and response to antidepressants and placebo: an analysis of the Food and Drug Administration database. J Clin Psychopharmacol 2002;22:40-45.

-62 Evans KR, Sills T, Wunderlich GR, McDonald HP: Worsening of depressive symptoms prior to randomization in clinical trials: a possible screen for placebo responders? J Psychiatr Res 2004;38:437-444.

-63 Stein DJ, Baldwin DS, Dolberg OT, Despiegel $\mathrm{N}$, Bandelow B: Which factors predict placebo response in anxiety disorders and major depression? An analysis of placebo-controlled studies of escitalopram. J Clin Psychiatry 2006;67:1741-1746.

64 Kirsch I, Deacon BJ, Huedo-Medina TB, Scoboria A, Moore TJ, Johnson BT: Initial severity and antidepressant benefits: a meta-analysis of data submitted to the Food and Drug Administration. PLoS Med 2008;5:e45.

65 Papakostas GI, Fava M: Does the probability of receiving placebo influence clinical trial outcome? A meta-regression of double-blind, randomized clinical trials in MDD. Eur Neuropsychopharmacol 2009;19:34-40.

- 66 Bridge JA, Birmaher B, Iyengar S, Barbe RP, Brent DA: Placebo response in randomized controlled trials of antidepressants for pediatric major depressive disorder. Am J Psychiatry 2009;166:42-49.

67 Brunoni AR, Lopes M, Kaptchuk TJ, Fregni F: Placebo response of non-pharmacological and pharmacological trials in major depression: a systematic review and meta-analysis. PLoS One 2009;4:e4824.

-68 Sinyor M, Levitt AJ, Cheung AH, Schaffer A, Kiss A, Dowlati Y, Lanctôt KL: Does inclusion of a placebo arm influence response to active antidepressant treatment in randomized controlled trials? Results from pooled and metaanalyses. J Clin Psychiatry 2010;71:270-279.

-69 Hunter AM, Cook IA, Leuchter AF: Impact of antidepressant treatment history on clinical outcomes in placebo and medication treatment of major depression. J Clin Psychopharmacol 2010;30:748-751.

70 Rutherford BR, Sneed JR, Tandler JM, Rindskopf D, Peterson BS, Roose SP: Deconstructing pediatric depression trials: an analysis of the effects of expectancy and therapeutic contact. J Am Acad Child Adolesc Psychiatry 2011;50:782-795.

71 Gueorguieva R, Mallinckrodt C, Krystal JH: Trajectories of depression severity in clinical trials of duloxetine: insights into antidepressant and placebo responses. Arch Gen Psychiatry 2011;68:1227-1237.

-72 Khin NA, Chen YF, Yang Y, Yang P, Laughren TP: Exploratory analyses of efficacy data from major depressive disorder trials submitted to the US Food and Drug Administration in support of new drug applications. J Clin Psychiatry 2011;72:464-472.

73 Mancini M, Wade AG, Perugi G, LenoxSmith A, Schacht A: Impact of patient selection and study characteristics on signal detection in placebo-controlled trials with antidepressants. J Psychiatr Res 2014;51:21-29.

74 Ilnyckyj A, Shanahan F, Anton PA, Cheang $\mathrm{M}$, Bernstein CN: Quantification of the placebo response in ulcerative colitis. Gastroenterology 1997;112:1854-1858.

75 Su C, Lichtenstein GR, Krok K, Brensinger CM, Lewis JD: A meta-analysis of the placebo rates of remission and response in clinical trials of active Crohn's disease. Gastroenterology 2004; $126: 1257-1269$.

76 Renna S, Cammà C, Modesto I, Cabibbo G, Scimeca D, Civitavecchia G, Mocciaro F, Orlando A, Enea M, Cottone M: Meta-analysis of the placebo rates of clinical relapse and severe endoscopic recurrence in postoperative Crohn's disease. Gastroenterology 2008;135: 1500-1509.

77 Pitz M, Cheang M, Bernstein CN: Defining the predictors of the placebo response in irritable bowel syndrome. Clin Gastroenterol Hepatol 2005;3:237-247.

78 Patel SM, Stason WB, Legedza A, Ock SM, Kaptchuk TJ, Conboy L, Canenguez K, Park JK, Kelly E, Jacobson E, Kerr CE, Lembo AJ: The placebo effect in irritable bowel syndrome trials: a meta-analysis. Neurogastroenterol Motil 2005; 17:332-340.

79 Dorn SD, Kaptchuk TJ, Park JB, Nguyen LT, Canenguez K, Nam BH, Woods KB, Conboy LA, Stason WB, Lembo AJ: A meta-analysis of the placebo response in complementary and alternative medicine trials of irritable bowel syndrome. Neurogastroenterol Motil 2007; 19:630-637.

80 Ford AC, Moayyedi P: Meta-analysis: factors affecting placebo response rate in the irritable bowel syndrome. Aliment Pharmacol Ther 2010;32:144-158.

-81 Talley NJ, Locke GR, Lahr BD, Zinsmeister AR, Cohard-Radice M, D'Elia TV, Tack J, Earnest DL: Predictors of the placebo response in functional dyspepsia. Aliment Pharmacol Ther 2006;23:923-936.

82 Enck P, Vinson B, Malfertheiner P, Zipfel S, Klosterhalfen S: The placebo response in functional dyspepsia - reanalysis of trial data. Neurogastroenterol Motil 2009;21: 370-377.

83 de Craen AJ, Moerman DE, Heisterkamp SH, Tytgat GN, Tijssen JG, Kleijnen J: Placebo effect in the treatment of duodenal ulcer. $\mathrm{Br} \mathrm{J}$ Clin Pharmacol 1999;48:853-860.

84 Yuan YH, Wang C, Yuan Y, Hunt RH: Metaanalysis: incidence of endoscopic gastric and duodenal ulcers in placebo arms of randomized placebo-controlled NSAID trials. Aliment Pharmacol Ther 2009;30:197-209.

-85 Cremonini F, Ziogas DC, Chang HY, Kokkotou E, Kelley JM, Conboy L, Kaptchuk TJ, Lembo AJ: Meta-analysis: the effects of placebo treatment on gastro-oesophageal reflux disease. Aliment Pharmacol Ther 2010;32: 29-42.

86 Lee S, Malhotra B, Creanga D, Carlsson M, Glue P: A meta-analysis of the placebo response in antimuscarinic drug trials for overactive bladder. BMC Med Res Methodol 2009; 9:55.

87 Thijs L, Amery A, Birkenhäger W, Bulpitt CJ, Clement D, de Leeuw P, De Schaepdryver A, Dollery C, Forette F, Henry JF, et al: Age-related effects of placebo and active treatment in patients beyond the age of 60 years: the need for a proper control group. J Hypertens 1990; 8:997-1002.

88 Cho HJ, Hotopf M, Wessely S: The placebo response in the treatment of chronic fatigue syndrome: a systematic review and metaanalysis. Psychosom Med 2005;67:301-313.

89 Freeman EW, Rickels K: Characteristics of placebo responses in medical treatment of premenstrual syndrome. Am J Psychiatry 1999;156:1403-1408.

90 Lamel SA, Myer KA, Younes N, Zhou JA, Maibach H, Maibach HI: Placebo response in relation to clinical trial design: a systematic review and meta-analysis of randomized controlled trials for determining biologic efficacy in psoriasis treatment. Arch Dermatol Res 2012;304:707-717.

91 Narkus A, Lehnigk U, Haefner D, Klinger R, Pfaar O, Worm M: The placebo effect in allergen-specific immunotherapy trials. Clin Transl Allergy 2013;3:42.

92 Kemeny ME, Rosenwasser LJ, Panettieri RA, Rose RM, Berg-Smith SM, Kline JN: Placebo response in asthma: a robust and objective phenomenon. J Allergy Clin Immunol 2007; 119:1375-1381.

93 Wang X, Shang D, Ribbing J, Ren Y, Deng C, Zhou T, Guo F, Lu W: Placebo effect model in asthma clinical studies: longitudinal metaanalysis of forced expiratory volume in $1 \mathrm{sec}$ ond. Eur J Clin Pharmacol 2012;68:11571166.

94 McCall WV, D’Agostino R Jr, Dunn A: A meta-analysis of sleep changes associated with placebo in hypnotic clinical trials. Sleep Med 2003;4:57-62.

95 McCall WV, D’Agostino R Jr, Rosenquist PB, Kimball J, Boggs N, Lasater B, Blocker $\mathrm{J}$ : Dissection of the factors driving the placebo effect in hypnotic treatment of depressed insomniacs. Sleep Med 2011;12: 557-564.

96 Tudur Smith C, Dwan K, Altman DG, Clarke M, Riley R, Williamson PR: Sharing individual participant data from clinical trials: an opinion survey regarding the establishment of a central repository. PLoS One 2014;9: e97886. 
\$97 Krogsbøll LT, Hróbjartsson A, Gøtzsche PC: Spontaneous improvement in randomised clinical trials: meta-analysis of three-armed trials comparing no treatment, placebo and active intervention. BMC Med Res Methodol 2009;9:1.

$>98$ Hofstra WB, Sterk PJ, Neijens HJ, Kouwenberg JM, Duiverman EJ: Prolonged recovery from exercise-induced asthma with increasing age in childhood. Pediatr Pulmonol 1995;20:177-183.

-99 Furukawa TA, Noma H, Caldwell DM, Honyashiki $M$, Shinohara K, Imai $H$, Chen $P$, Hunot V, Churchill R: Waiting list may be a nocebo condition in psychotherapy trials: a contribution from network meta-analysis. Acta Psychiatr Scand 2014;130:181-192.

100 Rutherford BR, Mori S, Sneed JR, Pimontel MA, Roose SP: Contribution of spontaneous improvement to placebo response in depression: a meta-analytic review. J Psychiatr Res 2012;46:697-702.
101 Posternak MA, Miller I: Untreated shortterm course of major depression: a metaanalysis of outcomes from studies using wait-list control groups. J Affect Disord 2001;66:139-146.

102 Hróbjartsson A, Gøtzsche PC: Placebo interventions for all clinical conditions. Cochrane Database Syst Rev 2010;CD003974.

103 Meissner K: Preferring patient-reported to observer-reported outcomes substantially influences the results of the updated systematic review on placebos by Hróbjartsson and Gøtzsche. J Intern Med 2005;257:394.

104 Kobak KA, Kane JM, Thase ME, Nierenberg AA: Why do clinical trials fail? The problem of measurement error in clinical trials: time to test new paradigms? J Clin Psychopharmacol 2007;27:1-5.

105 Rief W, Nestoriuc Y, Weiss S, Welzel E, Barsky AJ, Hofmann SG: Meta-analysis of the placebo response in antidepressant trials. J Affect Disord 2009;118:1-8.
06 Kirsch I: The emperor's new drugs: medication and placebo in the treatment of depression. Handb Exp Pharmacol 2014;225:291303.

107 Grelotti DJ, Kaptchuk TJ: Placebo by proxy. BMJ 2011;343:d4345.

108 Lidstone SC, Schulzer M, Dinelle K, Mak E, Sossi V, Ruth TJ, de la Fuente-Fernandez R, Phillips AG, Stoessl J: Effects of expectation on placebo-induced dopamine release in Parkinson disease. Arch Gen Psychiatry 2010;67:857-865.

109 Lou JS, Dimitrova DM, Hammerschlag R, Nutt J, Hunt EA, Eaton RW, Johnson SC, Davis MD, Arnold GC, Andrea SB, Oken BS: Effect of expectancy and personality on cortical excitability in Parkinson's disease. Mov Disord 2013;28:1257-1262.

110 Gøtzsche PC, Hróbjartsson A, Maric K, Tendal B: Data extraction errors in meta-analyses that use standardized mean differences. JAMA 2007;29:430-437. 